\title{
Association of nasopharyngeal viruses and pathogenic bacteria in children and their parents with and without HIV
}

\section{Tila Khan}

Indian Institute of Technology Kharagpur

\section{Ranjan Saurav Das}

Indian Institute of Technology Kharagpur

\section{Amrita Chaudhary}

Indian Institute of Technology Kharagpur

Jyotirmoy Chatterjee

Indian Institute of Technology Kharagpur

Sangeeta Das Bhattacharya ( $\nabla$ sangeeta@smst.iitkgp.ac.in )

Indian Institute of Technology Kharagpur https://orcid.org/0000-0001-6898-7911

\section{Research}

Keywords: HIV-infected children, respiratory virus, bacteria, pneumococcus, virus-bacteria interaction, carriage density, rhinovirus, adenovirus

Posted Date: January 14th, 2021

DOl: https://doi.org/10.21203/rs.3.rs-36198/v2

License: (c) (i) This work is licensed under a Creative Commons Attribution 4.0 International License. Read Full License

Version of Record: A version of this preprint was published at Pneumonia on May 5th, 2021. See the published version at https://doi.org/10.1186/s41479-021-00088-5. 


\section{Abstract}

Background: Bacteria and respiratory viruses co-occur in the nasopharynx, and their interactions may impact pathogenesis of invasive disease. Associations of viruses and bacteria in the nasopharynx may be affected by HIV.

Methods: We conducted a nested case-control study from a larger cohort study of banked nasopharyngeal swabs from families with and without HIV in West Bengal India, to look at the association of viruses and bacteria in the nasopharynx of parents and children when they are asymptomatic. Quantitative polymerase chain reaction for 4 bacteria and 21 respiratory viruses was run on 92 random nasopharyngeal swabs from children--49 from children living with HIV (CLH) and 43 from HIV uninfected children(HUC) - and 77 swabs from their parents (44 parents of CLH and 33 parents of HUC).

Results: Bacteria was found in $67 \%$ of children, viruses in $45 \%$, and both in $27 \%$ of child samples. Staphylococcus aureus (53\%) was the most common bacteria, followed by Streptococcus pneumoniae (pneumococcus) $(37 \%)$ in children and parents $(53 \%, 20 \%)$. Regardless of HIV status, viruses were detected in higher numbers $(44 \%)$ in children than their parents $(30 \%)(p=0.049)$, particularly rhinovirus $(p=0.02)$. Human rhinovirus was the most frequently found virus in both $\mathrm{CLH}$ and HUC. Children with adenovirus were at six times increased risk of also having pneumococcus (Odds ratio OR 6, 95\% $\mathrm{Cl} 1.12$ 31.9) regardless of HIV status. In addition, the presence of rhinovirus in children was associated with increased pneumococcal density (Regression coeff 4.5, 1.14-7.9). In CLH the presence of rhinovirus increased the risk of pneumococcal colonization by nearly sixteen times (OR 15.6, 1.66-146.4) and pneumococcus and $S$. aureus dual colonization by nearly nine times (OR 8.7).

Conclusions Children more frequently carried viruses regardless of HIV status. In CLH the presence of rhinovirus, the most frequently detected virus, significantly increased co-colonization with pneumococcus and $S$. aureus.

\section{Introduction}

The nasopharyngeal ecosystem composed of respiratory viruses and bacteria is dynamic [1, 2]. Its composition is affected by host, pathogen, and external factors [2,3]. Underlying HIV infection may affect the density and balance of bacteria and viruses in the nasopharyngeal space.

HIV infected individuals have a high burden of invasive disease from respiratory viruses, and bacteria that may colonize the nasopharynx [4,5]. HIV increases the risk of pneumococcal and $S$. aureus disease 40-300 times, and nasopharyngeal bacterial colonization usually precedes invasive disease $[5,6]$. The association between pneumococcus and $S$. aureus is typically negative in healthy individuals, where if one is present the other usually is not, but in HIV infected individuals, particularly in children living with HIV (CLH), this negative interaction disappears, and CLH are more likely to have dual colonization [7-10]. 
The carriage density of potentially pathogenic bacteria correlates with pathogenesis, transmission, disease severity, prognosis, and is affected by underlying HIV infection [11-13]. In South Africa, higher carriage density of pneumococcus has been observed in archived nasopharyngeal swabs from CLH compared to HIV uninfected children (HUC) [14]. We also found increased pneumococcal density in CLH compared to HUC [15]. Increased pneumococcal density appears to be an important prognostic marker of pneumococcal pneumonia in adults living with HIV [13].

Respiratory viral infections increase the carriage density of bacteria, specifically pneumococcus, and may impact prognosis in CLH [16]. In hospitalized children with pneumonia in South Africa, 78\% had viral infections and CLH specifically, had increased risk of death [17]. Influenza infection in particular was associated with pneumococcal pneumonia in this population.

Access to influenza and pneumococcal conjugate vaccines (PCV) need to reflect these differences in colonization and disease in individuals with HIV, especially in low- and middle-income countries. India has the largest population burden of pediatric HIV outside of sub-Saharan Africa [18], and acute respiratory illness (ARI) is the most common presentation for CLH in India [19]. Vaccine access to PCVs and influenza vaccines are limited for Indian CLH. Understanding nasopharyngeal ecology, the association between viruses with bacteria, and bacterial density in high-risk families could help inform evolving vaccine policy [20-22].

Studies have been focused on the epidemiology of ARI, but not necessarily on the interaction between commensal microbiota and viruses that have the potential to cause severe disease in individuals living with HIV $[19,23]$. This study investigates the bacteria and viruses within the nasopharynx, and the association of viruses with bacteria in high-risk families in West Bengal where both children and adults are living with HIV, and access to influenza and pneumococcal vaccines are limited.

\section{Materials And Methods}

\section{Study design}

From February 2012 to October 2014, we conducted an interventional prospective cohort study to look at the impact of monovalent Haemophilus influenzae type b conjugate vaccine (HibCV) and the 13-valent PCV (PCV13), on nasopharyngeal carriage in children living with and without HIV and their unvaccinated parents, in two rural districts of West Bengal India [24, 25]. During this time, HibCV was introduced in certain states in India but was not part of the program for CLH, and pneumococcal conjugate vaccines were not introduced in India until May 2017. Families living with HIV presenting for routine care were recruited from the antiretroviral treatment center at Midnapore Medical College \& Hospital. Families without HIV were recruited from the Hijli Rural Hospital-Kharagpur, a primary health center. None of the study children or their parents had received either HibCV or PCV13 before.

Children living with HIV ( $\mathrm{N}=123 ; 2-14$ years of age) received two doses of catch-up HibCV and one dose of PCV13, and the HIV uninfected children (HUC) $(\mathrm{N}=44 ; 2-5$ years of age) received a single dose each of 
HibCV and PCV13 at different time points. To look at the nasopharyngeal carriage, nasopharyngeal (NP) swabs were longitudinally collected from six scheduled visits over a period of 30 months from families living with HIV, and four visits from HIV unaffected families, before and two months after each immunization. We banked over $1800 \mathrm{NP}$ swabs which were collected from children and one of their parents at each visit during the entire study. At each visit the child's illness detail history, antibiotic intake history, vaccination history, ART status, Trimethoprim/Sulfomethoxazole (TMP/SMX) prophylaxis status, latest CD 4 count, body weight, height and temperature were noted proximate to swab collection. Nasopharyngeal calcium alginate swabs (Puritan) were collected in $1 \mathrm{~mL}$ of skim milk tryptone glucose glycerol (STGG) media, transported at $-4^{\circ} \mathrm{C}$, and banked within 1 hour at $-80^{\circ} \mathrm{C}$, at the Indian Institute of Technology (IIT)-Kharagpur.

Hib, pneumococcus, and $S$. aureus were identified by conventional culture methods. HibCV immunization was associated with a significant reduction and a near disappearance in the nasopharyngeal carriage of $\mathrm{Hib}$ in CLH and HUC by the last visit [24]. There was no difference in acquisition of vaccine type pneumococcus after one dose of PCV13 in either CLH or HUC [25].

As part of this retrospective nested case-control study, a random selection of 169 archived NP swabs were analyzed by multiplex real time PCR: 92 swabs from 49 CLH and 43 HUC; and 77 from 44 parents of $\mathrm{CLH}$ (PCLH), and 33 parents of HUC (PHUC). These swabs came from the first baseline visit (prevaccination; $26 \mathrm{CLH}, 23 \mathrm{HUC}, 24 \mathrm{PCLH}, 15 \mathrm{PHUC}$ ) and from the last visit (post HibCV and two months post PCV-13 vaccination; $23 \mathrm{CLH}, 20 \mathrm{HUC}, 20 \mathrm{PCLH}, 18 \mathrm{PHUC}$ ). Swabs from both the visits were combined and subjected to multiplex real time polymerase chain reaction (PCR).

\section{Multiplex quantitative real time PCR}

Bacterial DNA and viral RNA/DNA was extracted from $400 \mu \mathrm{L}$ of NP swabs with the RTP pathogen kit (Cat No: 1040500200 , Stratec $\left.{ }^{\circledR}\right)$. The genomes were subjected to quantitative multiplex real-time reverse transcription-polymerase chain reaction (rRT-PCR), for detection of respiratory viruses including human adenovirus, human bocavirus, human coronavirus (NL63, 229E, OC43 and HKU1229), enterovirus, influenza A virus, influenza A H1N1 virus, influenza B virus, human metapneumovirus $A / B$, human parainfluenza virus 1, 2, 3 and 4, human parechovirus, human rhinovirus, RSV A/B, and bacteria including Streptococcus pneumoniae, Staphylococcus aureus, Haemophilus influenzae type b, Chlamydia pneumoniae, and Mycoplasma pneumoniae as part of the FTD Respiratory pathogens 21 plus kit (Cat No: FTD-2+.1-64, FTD Diagnostics $\left.{ }^{\circledR}\right)$. Samples with cycle threshold (Ct) value $\leq 38$ were considered positive. Bacterial loads were calculated using standards provided with the kit, in genomic copies $/ \mathrm{mL}$ and $\log _{10}$ transformed.

\section{Statistical Analysis}

The data was entered into Epi Info 7 (CDC, Atlanta) and statistically analyzed by Stata version 13.1 (STATA Corporation). The bacterial and viral detection rates were defined as the percentage of samples that are positive for a particular bacterium or viral nucleic acid by PCR. Viral subtypes from one group 
were pooled since rates were low. Categorical variables were analyzed by $\chi^{2}$ test, and Wilcoxon rank-sum test was used for continuous. The nutritional status of children was measured by weight-for-age-z scores (WAZ), and height-for-age-Z scores (HAZ). Children with Z scores -2 to -3 were categorized as moderately malnourished and below -3 as severely malnourished [26]. CLH were categorized into immunologic categories based on CD4 counts [27]. Risk factor analysis for binary outcomes was done by logistic regression, and by linear regression for ordinal outcomes.

\section{Results}

\section{Demographic characteristics}

The demographics are described in Table 1. The median age of CLH was 4.8 years and 3.5 for HUC. CLH were malnourished and stunted as compared to HUC [WAZ for CLH -2.456 vs. -1.33 for HUC, $p=$ $<0.001$ ]; [HAZ for CLH-1.89 vs. -.92 for HUC, $p=<0.001$ ]. $98 \%$ of mothers of CLH were living with HIV. Mothers contributed $92 \%$ of all parental swabs.

\section{Clinical characteristics}

Nearly $36 \%$ (18/49) of CLH were on antiretroviral treatment (ART) and $51 \%$ were on TMP/SMX prophylaxis (Table 2). 53\% of parents of CLH were on ART. The majority of CLH had immune classification of severe $[15 / 49,(30 \%)]$ or moderate $[22 / 49,(45 \%)]$ disease. The median CD4 count was 650 cells $/ \mathrm{mm}^{3}$.

We noted the clinical history of children prior to NP specimen collection, and found $28 \%$ of CLH, and $21 \%$ of HUC, were sick in the past week. The major symptoms included fever, cough, rhinitis or diarrhea; however, during swab collection all children were afebrile $\left(<100.4{ }^{\circ} \mathrm{F}\right)$ and asymptomatic. Over $23 \%$ of CLH had a history of ear infection within one month prior to study, compared to $4 \%$ in HUC $(p=0.06)$, suggesting the increased risk of otitis media in CLH

\section{Nasopharyngeal bacteria and viruses in children versus parents}

A total of 169 NP swabs (92 from children; 77 from parents) were tested for viruses and 147 ( 83 from children, 64 from parents) for bacteria (Table 3). Bacteria were identified in $67 \%$ of the children, and $54 \%$ of parents. Staphylococcus aureus was the most common bacterium identified in children [53\%, 44/83], followed by Streptococcus pneumoniae [37.3\%, 31/83], and Chlamydia pneumoniae [2\%, 2/83]. Similar trends were seen in their parents, [S. aureus (53\%); pneumococcus (20\%)]. Higher rates of pneumococcus were found in children compared to parents $(p=0.02)$.

Pneumococcus with $S$. aureus were the most frequent bacteria co-detected (24\%) in children. Viruses were detected in higher numbers $(44 \%)$ in children than their parents $(30 \%)(p=0.049)$, particularly rhinovirus $(p=0.02)$. Viruses with bacteria were more frequently co-detected in children $(26 \%)$, than virus 
alone (3\%). For example, 13 out of 15 times rhinovirus was detected with bacteria, and adenovirus was found with bacteria 8 out of 9 times.

\section{Nasopharyngeal microbes and viruses in children with and without HIV}

\section{Bacteria detection}

Bacterial pathogens were tested in specimens from $43 \mathrm{CLH}, 40 \mathrm{HUC}$, and viruses in $49 \mathrm{CLH}, 43 \mathrm{HUC}$ (Table 4). Samples for bacterial testing were lower due to the loss of reactions in bacterial standards.

Bacteria were identified in $70 \%$ of $\mathrm{CLH}$ and $65 \%$ of HUC. S. aureus was identified in an increasing fashion in $\mathrm{CLH}$, as compared to HUC (63\% vs. $42 \% ; \mathrm{p}=0.06)$. Similar pneumococcus and $C$. pneumoniae rates were found in CLH and HUC (37\%; $2 \%$ each). Nearly 69\% (11/16) of CLH with pneumococcus and $51 \%$ (14/27) of CLH with $S$. aureus were on TMP/SMX prophylaxis. This suggests TMP/SMX did not decrease their risk for carriage. Co-occurrence of pneumococcus with $S$. aureus was found more often in CLH $(30 \%)$, than in HUC $(17 \%)$, although not significant $(p=0.17)$. We could not detect Hib by PCR in both the groups regardless of HibCV vaccination status.

\section{Respiratory virus detection}

In the 92 samples tested, viruses were detected in $41 \%$ of CLH and $49 \%$ of HUC. Rhinovirus and adenovirus were most frequently detected in CLH ( $14 \%$ each), followed by bocavirus $4 \%$, RSV $2 \%$, coronavirus- $2292 \%$, human metapneumovirus $2 \%$ and human parainfluenza- 3 virus ( $2 \%$ ). Of interest, viruses were identified mainly in children with stage 2 and 3 HIV disease (13/14), than stage $1(1 / 14)(p=$ $<0.001)$. $57 \%$ of CLH with viral positivity were not on ART. Rhinovirus was also most frequent in HUC (18\%). Influenza B was identified only in HUC (9\%). Being on an antibiotic in the past week, increased the risk of virus detection by 3.85 times, $(95 \% \mathrm{Cl} 1.05-14, \mathrm{p}=0.04)$.

\section{Virus-bacteria co-detection}

The co-occurrence of $\geq 1$ bacteria with $\geq 1$ viruses was found in $28 \%$ of $\mathrm{CLH}$, and $25 \%$ of HUC. The co-occurrence was mainly found in children with stage 2 and stage 3 HIV disease (11/12), as compared to stage $1(1 / 12)(p<0.001)$. Interestingly, wood used for cooking within households, increased the risk of virus (OR 3.09, 1.0-9.21, $\mathrm{p}=0.042)$ and virus-bacteria detection (OR 4.75, 1.2-17, $\mathrm{p}=0.019)$ among children, suggesting indoor air pollution may increase the risk for viral circulation.

\section{Nasopharyngeal bacteria and viruses identified in parents with and without HIV}

Bacteria were tested in 33 PCLH and 31 PHUC specimens, and viruses in 44 PCLH and 33 PHUC. Bacteria were detected in $51 \%$ of PCLH and $58 \%$ of PHUC. S. aureus was most frequent in both PCLH (51\%) and PHUC (58\%). Similar rates of pneumococcus (20-21\%) were detected in both parents, and their children. Viruses were detected in $34 \%$ of PCLH and $27 \%$ of PHUC. Adenovirus was most common in 
PCLH (11\%), and RSV in PHUC (12\%). Virus-bacteria co-detection was found in $16 \%$ of PHUC and $12 \%$ of PCLH.

\section{Co-detection of nasopharyngeal bacteria with viruses}

Virus-bacteria co-detections were found in $12 \mathrm{CLH}$ and $10 \mathrm{HUC}$. Of the $12 \mathrm{CLH}, 7$ had co-occurrence of $S$. pneumoniae $+S$. aureus with viruses. The remaining $5 \mathrm{CLH}$ had co-occurrence of viruses with pneumococcus (2), or $S$. aureus (3). Among the HUC, viruses were co-detected with pneumococcus (3), $S$. aureus (3), S. pneumoniae + S. aureus (3), or, C. pneumoniae (1). Among parents, viruses were co-detected only with $S$. aureus $(8 / 64)$.

\section{Nasopharyngeal carriage in children with and without history of symptoms}

A history of respiratory symptoms in the past week was associated with more than 4 times increased risk of virus detection in children (OR 4.2; 1.5-11.7; $\mathrm{p}=0.005)$, and 3.65 times virus-bacteria co-detection (OR $3.65 ; 1.3-10 ; p=0.01)$. CLH with symptoms in the past week, had 6 times increased risk of virus detection (6.44; $1.62-25 ; p=0.008)$, as compared to 2 fold in HUC $(2.6 ; .56-12 ; p=0.22)$.

\section{Association of viruses with S. pneumoniae and its nasopharyngeal density in children}

S. pneumoniae was associated with co-occurrence of viral species in children regardless of their HIV status (OR 3.9) (Table 5), particularly adenovirus co-detection increased the likelihood of pneumococcal detection six fold $(p=0.036)$. Increased pneumococcal density was seen with co-detection of viruses (Coeff 3.6), multiple viruses (Coeff 5), and rhinovirus specifically (Coeff 4.5) in children regardless of their HIV status.

In $\mathrm{CLH}$, the presence of rhinovirus increased the risk of pneumococcal colonization by nearly sixteen times (OR 15.6), and pneumococcus and $S$. aureus dual colonization increased nearly 9 times in the presence of rhinovirus (OR 8.7).

\section{Discussion}

This is the first report from India about household level prevalence and association of respiratory viruses with bacteria in parents and children in the context of HIV, using multiplex real time PCR. In this study, we found higher prevalence of bacteria and viruses in children than their parents regardless of HIV status. This suggests parents or caregivers are at increased risk of exposure to viruses and bacteria in households with children. This is in agreement with the results of our immunization study where we 
found bacterial carriage within the households- carriage in children predicted the carriage in parents and thus immunization in children indirectly impacts the carriage in unvaccinated adults.

A majority of the CLH had moderate to severe HIV disease and were not on ART, which increased their risk for bacteria and virus detection [28]. CLH living in households with adults with HIV who are also at high risk, puts these families at increased risk for severe invasive diseases. Similar to our findings, others have reported more $S$. aureus carriage in CLH, as compared to HUC [29-31], while some did not [10]. Although the swabs in this study came from an unimmunized and HibCV and PCV13-immunized cohort of children, the overall pneumococcal carriage was not affected. Rather, we detected higher rates of pneumococcus (37\%) by PCR than by culture detected pre $(31 \%)$ and post PCV13 $(28 \%)$ immunization $[25,36]$. Further, we observed in the past that the point prevalence of pneumococcus did not change with one dose of PCV13 in both CLH and HUC [25]. The differences were noted only in serotypes and the density of carriage [25,32]. The overall rates of pneumococcus in CLH were similar to studies from Brazil (28\%) [33], and Indonesia (46\%) [34]. While reasons are not clear, similar pneumococcal detection rates have been seen between CLH and HUC by us in this cohort [25], in Brazil [33], Mozambique [35], and South Africa [7]. Serotype specific carriage may provide more information; as seen earlier, HIV infection increased the risk of colonization of non-vaccine type and antibiotic resistant pneumococcal serotypes [36]. TMP/SMX prophylaxis did not appear to influence the carriage of pneumococcus or $S$. aureus. This could be due to the resistance of pneumococcal isolates to TMP/SMX, as we saw in $98 \%$ of isolates in the past [36].

The co-colonization of otherwise competing pneumococcus and $S$. aureus in those living with HIV could be immune-mediated due to decrease in pneumococcal-specific CD $4^{+} T$ cells in HIV infected individuals [37]. The interference, or negative association, between pneumococcus and $S$. aureus seen in HIV uninfected children, has been observed following antiretroviral treatment in CLH [7].

Rhinovirus and pneumococcus have been observed to be positively associated in healthy children under$2[2,38]$. An Indian study reported rhinovirus with $S$. aureus in symptomatic individuals living with HIV [39]. We also found a positive association of rhinovirus, $S$. aureus, and pneumococcus in CLH, when they were asymptomatic.

Viral infections commonly cause hospitalizations in $\mathrm{CLH}$, and rhinovirus and adenovirus in particular are responsible for LRTI and acute otitis media (AOM) in both $\mathrm{HUC}$ and $\mathrm{CLH}[3,17,40]$. Higher rates of viruses were detected in children regardless of HIV, particularly rhinovirus. Viruses Rhinovirus has been the most frequently identified virus in asymptomatic children, also found in a healthy control group of a childhood pneumonia study in Asia, Africa and South America [2, 41, 42]. The detection of virus in the nasopharynx may suggest asymptomatic carriage, subclinical infection, or prolonged viral shedding from recent symptomatic infection, or a past infection $[43,44]$. CLH may shed viruses for a longer time, and this may increase their risk for secondary bacterial infections leading to pneumonia and $A O M$, and also increase risk of infections within families where both adults and children are living with HIV $[20,45,46]$. 
Otitis media and LRTI cause significant morbidity and mortality in CLH. [47]. Bacterial and viral interactions specifically involving rhinovirus, adenovirus, pneumococcus, $S$. aureus, and nontypeable $H$. influenzae are particularly important in the pathogenesis of these conditions [3]. In studies in South Africa with HUC, CLH, and HIV exposed uninfected children, CLH had the same spectrum of pathogens for these conditions; however, they had increased risk of mortality [17].

Association of increased pneumococcal density with viruses, has been observed during asymptomatic [48], and symptomatic viral infections $[16,21,49]$. Respiratory viral co-infections are demonstrated to be associated with invasive pneumococcal pneumonia [21]. Viral co-detection with increasing pneumococcal load without producing symptoms, may suggest that viruses promote growth and transmission of bacterial colonizers in the nasopharynx, thus predisposing individuals to complications of upper respiratory tract infections [48]. Rhinovirus co-infections were associated with increasing pneumococcal density during episodes of ARI in young children in rural Peru [50]. A Finnish study showed rhinovirus circulation was associated with invasive pneumococcal disease (IPD) in children [45]. Mechanistic in vitro studies support that rhinovirus increases pneumococcal adherence, through the expression of platelet-activating factor receptor [51], and disrupts the epithelial barrier functions thus promoting the binding, translocation, and persistence of bacteria [52]. Similarly, adenovirus has been correlated with IPD in children [21, 53] and in vitro [54].

The major findings of this study are the detection of viruses with increasing pneumococcal density in asymptomatic children, and rhinovirus co-detection with pneumococcus in CLH compared to agematched HUC. Association between pneumococcus, S. aureus, and rhinovirus in CLH, supports the increased risk of polymicrobial pneumonias in CLH. Pneumococcal conjugate vaccines impact the nasopharyngeal ecology and the risk of LRTI and AOM in adults and children with HIV $[7,55,56]$.

The study is limited in its sample size, therefore confidence intervals were wide for OR, and we could not do multivariate analysis for association between microbes. The swabs were part of a vaccine impact study and were combined from pre and post immunization visits, so there was an inherent bias in the selection; however, the overall pneumococcal carriage was not affected. The clinical relevance of viral activity with increasing pneumococcal density in asymptomatic children requires further study through well designed cohort studies.

Pneumococcal-viral interactions are complex. Larger longitudinal studies are needed to understand the viral-bacterial dynamics in high-risk families, in both asymptomatic, and symptomatic situations. Viral load, and host immune responses, may better differentiate asymptomatic versus active viral infections [57]. India has a huge burden of HIV and pneumonia. Pneumococcal vaccines are being rolled-out in the Indian UIP but seasonal influenza vaccines are still not part of government programs and neither are available in programs for individuals living with HIV. It is essential to think about access to vaccines for children and adults with HIV to mitigate respiratory infections [58]. This study is timely in looking at the association of pneumococcus with viruses in this high-risk group. 
In conclusion, this study demonstrates high detection of viruses and bacteria in asymptomatic children with and without HIV and shows that pneumococcal density increases in the presence of viruses.

\section{Declarations}

Ethics approval and consent to participate: The study was approved by the Institute Ethical Committee of Indian Institute of Technology-Kharagpur. Written informed consent forms were obtained from all study participants prior to start of the study

Consent for publication: Written informed consent forms obtained from all participants included consent for publication.

Availability of data and materials: The datasets during and/or analyzed during the current study available from the corresponding author on reasonable request.

Competing interests: The authors declare that they have no competing interests

Funding: This work was supported by the Robert Austrian Research Awards Committee 2016 for pneumococcal vaccinology under Grant [Robert Austrian Research Award 2016]. The funding body had no role in the design of the study and collection, analysis, and interpretation of data and in writing the manuscript.

Authors' contributions: TK conceptualized the study, processed the samples, analyzed the data, interpreted the data and wrote the manuscript. RSD collected samples, processed samples and did data entry in Epilnfo. AC helped in running PCR. JC helped in the analysis of data and writing the manuscript. SDB conceptualized the study, conducted the field study, interpreted the data and wrote the manuscript. All authors read and approved the final manuscript.

\section{References}

[1] Bosch AA, Biesbroek G, Trzcinski K, Sanders EA, Bogaert D. Viral and bacterial interactions in the upper respiratory tract. PLoS Pathog. 2013;9:e1003057.

[2] van den Bergh MR, Biesbroek G, Rossen JW, de Steenhuijsen Piters WA, Bosch AA, van Gils EJ, et al. Associations between pathogens in the upper respiratory tract of young children: interplay between viruses and bacteria. PLoS One. 2012;7:e47711.

[3] Madhi SA, Govender N, Dayal K, Devadiga R, Van Dyke MK, van Niekerk N, et al. Bacterial and Respiratory Viral Interactions in the Etiology of Acute Otitis Media in HIV-infected and HIV-uninfected South African Children. Pediatr Infect Dis J. 2015;34:753-60.

[4] O'Brien KL, Wolfson LJ, Watt JP, Henkle E, Deloria-Knoll M, McCall N, et al. Burden of disease caused by Streptococcus pneumoniae in children younger than 5 years: global estimates. Lancet. 2009;374:893- 
902.

[5] Madhi SA, Petersen K, Madhi A, Khoosal M, Klugman KP. Increased disease burden and antibiotic resistance of bacteria causing severe community-acquired lower respiratory tract infections in human immunodeficiency virus type 1-infected children. Clin Infect Dis. 2000;31:170-6.

[6] Mulu W, Yizengaw E, Alemu M, Mekonnen D, Hailu D, Ketemaw K, et al. Pharyngeal colonization and drug resistance profiles of Morraxella catarrrhalis, Streptococcus pneumoniae, Staphylococcus aureus, and Haemophilus influenzae among HIV infected children attending ART Clinic of Felegehiwot Referral Hospital, Ethiopia. PLoS One. 2018;13:e0196722.

[7] Madhi SA, Izu A, Nunes MC, Violari A, Cotton MF, Jean-Philippe P, et al. Longitudinal study on Streptococcus pneumoniae, Haemophilus influenzae and Staphylococcus aureus nasopharyngeal colonization in HIV-infected and -uninfected infants vaccinated with pneumococcal conjugate vaccine. Vaccine. 2015;33:2662-9.

[8] Bhattacharya SD, Niyogi SK, Bhattacharyya S, Arya BK, Chauhan N, Mandal S. Associations between potential bacterial pathogens in the nasopharynx of HIV infected children. Indian J Pediatr. 2012;79:144753.

[9] McNally LM, Jeena PM, Gajee K, Sturm AW, Tomkins AM, Coovadia HM, et al. Lack of association between the nasopharyngeal carriage of Streptococcus pneumoniae and Staphylococcus aureus in HIV1-infected South African children. J Infect Dis. 2006;194:385-90.

[10] Madhi SA, Adrian P, Kuwanda L, Cutland C, Albrich WC, Klugman KP. Long-term effect of pneumococcal conjugate vaccine on nasopharyngeal colonization by Streptococcus pneumoniae--and associated interactions with Staphylococcus aureus and Haemophilus influenzae colonization-in HIVInfected and HIV-uninfected children. J Infect Dis. 2007;196:1662-6.

[11] Siegel SJ, Weiser JN. Mechanisms of Bacterial Colonization of the Respiratory Tract. Annu Rev Microbiol. 2015;69:425-44.

[12] Bogaert D, De Groot R, Hermans PW. Streptococcus pneumoniae colonisation: the key to pneumococcal disease. Lancet Infect Dis. 2004;4:144-54.

[13] Albrich WC, Madhi SA, Adrian PV, van Niekerk N, Telles JN, Ebrahim N, et al. Pneumococcal colonisation density: a new marker for disease severity in HIV-infected adults with pneumonia. BMJ Open. 2014;4:e005953.

[14] Olwagen CP, Adrian PV, Madhi SA. Evaluation of the impact of HIV-1 infection and density of common nasopharyngeal bacterial colonizers in South African children immunized with 7-valent pneumococcal conjugate vaccine. Vaccine. 2019. 
[15] Khan T, Das RS, Arya BK, Chaudhary A, Chatterjee J, Das Bhattacharya S. Impact of pneumococcal conjugate vaccine on the carriage density of Streptococcus pneumoniae and Staphylococcus aureus in children living with HIV: a nested case-control study. Hum Vaccin Immunother. 2020:1-5.

[16] Thors V, Christensen H, Morales-Aza B, Oliver E, Sikora P, Vipond I, et al. High-density Bacterial Nasal Carriage in Children Is Transient and Associated With Respiratory Viral Infections-Implications for Transmission Dynamics. Pediatr Infect Dis J. 2019;38:533-8.

[17] Cohen C, Walaza S, Moyes J, Groome M, Tempia S, Pretorius M, et al. Epidemiology of viralassociated acute lower respiratory tract infection among children $<5$ years of age in a high HIV prevalence setting, South Africa, 2009-2012. Pediatr Infect Dis J. 2015;34:66-72.

[18] UNAIDS. UNAIDS Global HIV and AIDS statistics- 2018 Fact sheet. 2019.

[19] Dhaka G, Sherwal BL, Saxena S, Rai Y, Chandra J. Current trends in opportunistic infections in children living with HIV/AIDS in a tertiary care hospital in Northern India. Indian J Sex Transm Dis AIDS. 2018;38:142-6.

[20] O'Brien KL, Walters MI, Sellman J, Quinlisk P, Regnery H, Schwartz B, et al. Severe pneumococcal pneumonia in previously healthy children: the role of preceding influenza infection. Clin Infect Dis. 2000;30:784-9.

[21] Wolter N, Tempia S, Cohen C, Madhi SA, Venter M, Moyes J, et al. High nasopharyngeal pneumococcal density, increased by viral coinfection, is associated with invasive pneumococcal pneumonia. J Infect Dis. 2014;210:1649-57.

[22] Ruohola A, Pettigrew MM, Lindholm L, Jalava J, Raisanen KS, Vainionpaa R, et al. Bacterial and viral interactions within the nasopharynx contribute to the risk of acute otitis media. J Infect. 2012;66:247-54.

[23] Shailaja VV, Pai LA, Mathur DR, Lakshmi V. Prevalence of bacterial and fungal agents causing lower respiratory tract infections in patients with human immunodeficiency virus infection. Indian $\mathrm{J}$ Med Microbiol. 2004;22:28-33.

[24] Arya BK, Bhattacharya SD, Sutcliffe CG, Saha MK, Bhattacharyya S, Niyogi SK, et al. Immunogenicity and safety of two doses of catch-up immunization with Haemophilus influenzae type b conjugate vaccine in Indian children living with HIV. Vaccine. 2016;34:2267-74.

[25] Arya BK, Bhattacharya SD, Sutcliffe CG, Ganaie F, Bhaskar A, Bhattacharyya S, et al. Nasopharyngeal Pneumococcal Colonization and Impact of a Single Dose of 13-Valent Pneumococcal Conjugate Vaccine in Indian Children With HIV and Their Unvaccinated Parents. Pediatr Infect Dis J. 2017;37:451-8.

[26] WHO. WHO global database on child growth and malnutrition. Department of Nutrition for Health and Development. 2006. 
[27] Selik RM, Mokotoff ED, Branson B, Owen SM, Whitmore S, Hall HI. Revised Surveillance Case Definition for HIV Infection - United States, 2014. Morbidity and Mortality Weekly Report 2014;63(RR03):1-10.

[28] McNally LM, Jeena PM, Gajee K, Thula SA, Sturm AW, Cassol S, et al. Effect of age, polymicrobial disease, and maternal HIV status on treatment response and cause of severe pneumonia in South African children: a prospective descriptive study. Lancet. 2007;369:1440-51.

[29] Raviglione MC, Mariuz P, Pablos-Mendez A, Battan R, Ottuso P, Taranta A. High Staphylococcus aureus nasal carriage rate in patients with acquired immunodeficiency syndrome or AIDS-related complex. Am J Infect Control. 1990;18:64-9.

[30] Nguyen MH, Kauffman CA, Goodman RP, Squier C, Arbeit RD, Singh N, et al. Nasal carriage of and infection with Staphylococcus aureus in HIV-infected patients. Ann Intern Med. 1999;130:221-5.

[31] Kinabo GD, van der Ven A, Msuya LJ, Shayo AM, Schimana W, Ndaro A, et al. Dynamics of nasopharyngeal bacterial colonisation in HIV-exposed young infants in Tanzania. Trop Med Int Health. 2013;18:286-95.

[32] Khan T, Das RS, Arya BK, Chaudhay A, Chatterjee J, Bhattacharya SD. Impact of pneumococcal conjugate vaccine on the carriage density of Streptococcus pneumoniae and Staphylococcus aureus in children living with HIV: a nested case-

control study. Hum Vaccin Immunother. 2019.

[33] Cardoso VC, Cervi MC, Cintra OA, Salathiel AS, Gomes AC. Nasopharyngeal colonization with Streptococcus pneumoniae in children infected with human immunodeficiency virus. J Pediatr (Rio J). 2006;82:51-7.

[34] Safari D, Kurniati N, Waslia L, Khoeri MM, Putri T, Bogaert D, et al. Serotype distribution and antibiotic susceptibility of Streptococcus pneumoniae strains carried by children infected with human immunodeficiency virus. PLoS One. 2014;9:e110526.

[35] Verani JR, Massora S, Acacio S, Dos Santos RT, Vubil D, Pimenta F, et al. Nasopharyngeal carriage of Streptococcus pneumoniae among HIV-infected and -uninfected children $<5$ years of age before introduction of pneumococcal conjugate vaccine in Mozambique. PLoS One. 2018;13:e0191113.

[36] Arya BK, Bhattacharya SD, Harigovind G, Das RS, Khan T, Ganaie F, et al. Streptococcus pneumoniae Acquisition and Carriage in Vaccine Naive Indian Children with HIV and their Parents: A Longitudinal Household Study. Indian J Pediatr. 2019;86:1002-10.

[37] Sepako E, Glennie SJ, Jambo KC, Mzinza D, Iwajomo OH, Banda D, et al. Incomplete recovery of pneumococcal CD4 T cell immunity after initiation of antiretroviral therapy in HIV-infected malawian adults. PLoS One. 2014;9:e100640. 
[38] Jacoby P, Watson K, Bowman J, Taylor A, Riley TV, Smith DW, et al. Modelling the co-occurrence of Streptococcus pneumoniae with other bacterial and viral pathogens in the upper respiratory tract. Vaccine. 2007;25:2458-64.

[39] Katiyar R, Agarwal V, Chowdhary S, Srivastava N, Gaur P, Dhole TN. Incidence of human rhinovirus coinfection with Staphylococcus aureus among HIV patients suffering from flu like illness. International Journal of Pharmaceutical Sciences and Research. 2017;51:4441-6.

[40] Nunes MC, Kuschner Z, Rabede Z, Madimabe R, Van Niekerk N, Moloi J, et al. Clinical epidemiology of bocavirus, rhinovirus, two polyomaviruses and four coronaviruses in HIV-infected and HIV-uninfected South African children. PLoS One. 2014;9:e86448.

[41] Moore HC, Jacoby P, Taylor A, Harnett G, Bowman J, Riley TV, et al. The interaction between respiratory viruses and pathogenic bacteria in the upper respiratory tract of asymptomatic Aboriginal and non-Aboriginal children. Pediatr Infect Dis J. 2010;29:540-5.

[42] Benet T, Sanchez Picot V, Messaoudi M, Chou M, Eap T, Wang J, et al. Microorganisms Associated With Pneumonia in Children $<5$ Years of Age in Developing and Emerging Countries: The GABRIEL Pneumonia Multicenter, Prospective, Case-Control Study. Clin Infect Dis. 2017;65:604-12.

[43] Jartti T, Jartti L, Peltola V, Waris M, Ruuskanen O. Identification of respiratory viruses in asymptomatic subjects: asymptomatic respiratory viral infections. Pediatr Infect Dis J. 2008;27:1103-7.

[44] Jansen RR, Wieringa J, Koekkoek SM, Visser CE, Pajkrt D, Molenkamp R, et al. Frequent detection of respiratory viruses without symptoms: toward defining clinically relevant cutoff values. J Clin Microbiol. 2011;49:2631-6.

[45] Peltola V, Heikkinen T, Ruuskanen O, Jartti T, Hovi T, Kilpi T, et al. Temporal association between rhinovirus circulation in the community and invasive pneumococcal disease in children. Pediatr Infect Dis J. 2011;30:456-61.

[46] Jansen AG, Sanders EA, A VDE, AM VANL, Hoes AW, Hak E. Invasive pneumococcal and meningococcal disease: association with influenza virus and respiratory syncytial virus activity? Epidemiol Infect. 2008;136:1448-54.

[47] Gray D, Zar HJ. Management of community-acquired pneumonia in HIV-infected children. Expert Rev Anti Infect Ther. 2009;7:437-51.

[48] DeMuri GP, Gern JE, Eickhoff JC, Lynch SV, Wald ER. Dynamics of Bacterial Colonization With Streptococcus pneumoniae, Haemophilus influenzae, and Moraxella catarrhalis During Symptomatic and Asymptomatic Viral Upper Respiratory Tract Infection. Clin Infect Dis. 2017;66:1045-53.

[49] Howard LM, Fan R, Zhu Y, Griffin MR, Edwards KM, Hartinger S, et al. Nasopharyngeal Pneumococcal Density Is Associated With Viral Activity but Not With Use of Improved Stoves Among Young Andean 
Children. Open Forum Infect Dis. 2017;4:ofx161.

[50] Fan RR, Howard LM, Griffin MR, Edwards KM, Zhu Y, Williams JV, et al. Nasopharyngeal Pneumococcal Density and Evolution of Acute Respiratory Illnesses in Young Children, Peru, $2009-2011$. Emerg Infect Dis. 2016;22:1996-9.

[51] Ishizuka S, Yamaya M, Suzuki T, Takahashi H, Ida S, Sasaki T, et al. Effects of rhinovirus infection on the adherence of Streptococcus pneumoniae to cultured human airway epithelial cells. J Infect Dis. 2003;188:1928-39.

[52] Sajjan U, Wang Q, Zhao Y, Gruenert DC, Hershenson MB. Rhinovirus disrupts the barrier function of polarized airway epithelial cells. Am J Respir Crit Care Med. 2008;178:1271-81.

[53] Ciruela P, Broner S, Izquierdo C, Hernandez S, Munoz-Almagro C, Pallares R, et al. Invasive pneumococcal disease rates linked to meteorological factors and respiratory virus circulation (Catalonia, 2006-2012). BMC Public Health. 2016;16:400.

[54] Hakansson A, Kidd A, Wadell G, Sabharwal H, Svanborg C. Adenovirus infection enhances in vitro adherence of Streptococcus pneumoniae. Infect Immun. 1994;62:2707-14.

[55] Bliss SJ, O'Brien KL, Janoff EN, Cotton MF, Musoke P, Coovadia H, et al. The evidence for using conjugate vaccines to protect HIV-infected children against pneumococcal disease. Lancet Infect Dis. 2008;8:67-80.

[56] Eskola J, Kilpi T, Palmu A, Jokinen J, Haapakoski J, Herva E, et al. Efficacy of a pneumococcal conjugate vaccine against acute otitis media. N Engl J Med. 2001;344:403-9.

[57] Heinonen S, Jartti T, Garcia C, Oliva S, Smitherman C, Anguiano E, et al. Rhinovirus Detection in Symptomatic and Asymptomatic Children: Value of Host Transcriptome Analysis. Am J Respir Crit Care Med. 2015;193:772-82.

[58] Sachdeva A. Pneumococcal Conjugate Vaccine Introduction in India's Universal Immunization Program. Indian Pediatr. 2017;54:445-6.

\section{Tables}

Table 1: Demographic characteristics of children and their parents 


\begin{tabular}{|c|c|c|c|}
\hline & $\begin{array}{l}\text { Children living with } \\
\text { HIV (CLH) }\end{array}$ & $\begin{array}{l}\text { HIV uninfected } \\
\text { children (HUC) }\end{array}$ & $\mathbf{P}$ \\
\hline$N$ & 49 & 43 & \\
\hline Age years, median (IQR25, IQR75) & $4.827(3.8,6.12)$ & $3.53(3.09,4.04)$ & $<0.001^{\star}$ \\
\hline Female child, n (\%) & $25(51)$ & $25(58)$ & \\
\hline WAZ median (IQR25, IQR75) & $-2.45(-3.63,-2.043)$ & $-1.33(-2.03,-.525)$ & $<0.001^{\star}$ \\
\hline HAZ median (IQR25, IQR75) & $-1.89(-2.76,-1.186)$ & $-.925(-1.69, .015)$ & $<0.001^{\star}$ \\
\hline Child school going, $\mathrm{n}(\%)$ & $27(55)$ & $28(65)$ & 0.223 \\
\hline Tuberculosis in house, $\mathrm{n}(\%)$ & $11(22)$ & $2(4)$ & 0.014 \\
\hline $\begin{array}{l}\text { Number of children in house, median } \\
\text { (IQR25, IQR75) }\end{array}$ & $2(2,2)$ & $2(1,2)$ & $0.001^{\star}$ \\
\hline $\begin{array}{l}\text { Number of rooms in house, median } \\
\text { (IQR25, IQR75) }\end{array}$ & $2(2,3)$ & $2(2,4)$ & 0.45 \\
\hline $\begin{array}{l}\text { Family income, median (IQR25, } \\
\text { IQR75) }\end{array}$ & $11362(9478,11362)$ & $7594(7594,9478)$ & 0.0004 \\
\hline \multicolumn{4}{|l|}{ Socioeconomic status ${ }^{\#}$} \\
\hline Lower, n (\%) & $0(0)$ & $2(4.7)$ & - \\
\hline Upper lower, n (\%) & $2(4)$ & $10(23)$ & 0.006 \\
\hline Middle, n (\%) & $20(41)$ & $29(67)$ & 0.01 \\
\hline Upper middle, $\mathrm{n}(\%)$ & $27(55)$ & $2(4.7)$ & $<0.00001$ \\
\hline \multicolumn{4}{|l|}{ Fuel used for cooking } \\
\hline Gas, n (\%) & $6(12)$ & $21(49)$ & .00012 \\
\hline Wood, n (\%) & $41(84)$ & $18(42)$ & .00003 \\
\hline Coal, n (\%) & $2(4)$ & $0(0)$ & - \\
\hline \multicolumn{4}{|l|}{ Parents } \\
\hline Mother alive, n (\%) & $47(96)$ & $43(100)$ & - \\
\hline Father alive, $\mathrm{n}(\%)$ & $27(55)$ & $43(100)$ & - \\
\hline Mother HIV infected, n (\%) & $46(98)$ & $N A^{\star \star}$ & - \\
\hline Father HIV infected, n (\%) & $22(45)$ & NA & - \\
\hline $\begin{array}{l}\text { Mothers' age years, median (IQR25, } \\
\text { IQR75) }\end{array}$ & $30(27,33)$ & $24(22,27)$ & $<0.001 *$ \\
\hline Mothers' schooling years, median & $7(3,9)$ & $9(7,10)$ & $0.0004^{*}$ \\
\hline
\end{tabular}


(IQR25, IQR75)

Parent on ART during study, $\mathrm{n}(\%)$

$26(53)$

NA

${ }^{*} \mathrm{p}<0.05$ significant; **Not applicable, "\#based on Kuppuswamy's Socioeconomic Status Scale 2012

Table 2: Clinical history of children living with and without HIV

\begin{tabular}{|c|c|c|}
\hline & $\begin{array}{l}\text { Children living with HIV } \\
\text { (CLH) }\end{array}$ & HIV uninfected children (HUC) \\
\hline $\mathrm{N}$ & 49 & 43 \\
\hline \multicolumn{3}{|l|}{ Immune category, n (\%) } \\
\hline None & $12(24)$ & - \\
\hline Moderate & $22(45)$ & - \\
\hline Severe & $15(30)$ & - \\
\hline Median CD4 count (IQR) & $650(392,912)$ & - \\
\hline On ART, n (\%) & $18(36)$ & - \\
\hline On TMP/SMX, n (\%) & $25(51)$ & - \\
\hline Median ART Duration (IQR), month & $3(2,5)$ & - \\
\hline HIV plasma load, median IQR & 2.57E4 (3.54E3, 1.36E5) & - \\
\hline Tuberculosis co-morbidity, n (\%) & $5(10)$ & 0 \\
\hline Ear infection history, n (\%) & $6 / 26(23)$ & $1 / 23(4)$ \\
\hline Past week sickness history, n (\%) & $14(28)$ & $10(23)$ \\
\hline Fever, n (\%) & $7(14)$ & $5(11)$ \\
\hline Cough, n (\%) & $7(14)$ & $6(14)$ \\
\hline Rhinorrhea, n (\%) & $2(4)$ & $5(11)$ \\
\hline Diarrhea, n (\%) & $1(2)$ & 0 \\
\hline Antibiotic intake during past week, $\mathrm{n}(\%)$ & $7(14)$ & $4(9.3)$ \\
\hline
\end{tabular}


Table 3

Nasopharyngeal bacteria and viruses identified in children and their parents

$\begin{array}{lll}\text { Children } & \text { Parents } & \text { P value } \\ \text { No. }(\%) & \text { No. }(\%) & \end{array}$

Bacterial detection

$\mathrm{N}$

83

64

No. of individuals with no bacteria*

$26(31)$

$26(40.6)$

0.24

No. of individuals with bacteria**

$56(67)$

$35(54.6)$

0.11

No. of individuals with bacteria only***

$34(41)$

$27(42)$

0.88

Total S. pneumoniae

$31(37)$

$13(20)$

0.02

Total S. aureus

$44(53)$

$34(53)$

0.98

Total C. pneumoniae

2 (2.4)

$24(29)$

$20(24)$

$1(1)$

0

$>1$ bacteria in one swab ${ }^{\#}$

S. pneumoniae + S. aureus

S. pneumoniae $+C$. pneumoniae

Virus detection

$\mathrm{N}$

92

77

Number of individuals with virus ${ }^{\# \#}$

$41(44.5)$

$23(30)$

0.049

Single virus only!

3 (3)

$9(11.7)$

0.03

Human rhinovirus

$15(16)$

$4(5)$

0.02

Human adenovirus

$9(10)$

$6(8)$

0.65

Human bocavirus

Influenza B virus

Respiratory Syncytial Virus

Human coronavirus

6 (6)

$4(4)$

2 (2)

$5(6.5)$

0.16

Human metapneumovirus

2 (2)

$1(1)$

0.66

Human parainfluenza virus

2 (2)

1 (1)

0

Human enterovirus

2 (2.6)

3 (4) 
Table 3

Nasopharyngeal bacteria and viruses identified in children and their parents

\begin{tabular}{|c|c|c|c|}
\hline & Children & Parents & $P$ value \\
\hline \multicolumn{4}{|c|}{ Viruses + bacteria co-detection } \\
\hline $\mathrm{N}$ & 83 & 64 & \\
\hline Total viruses + bacteria! & $22(26.5)$ & $9(4)$ & 0.06 \\
\hline Single virus + bacteria & $12(14.4)$ & $8(12.5)$ & 0.73 \\
\hline Mixed virus + bacteria & $10(12)$ & $1(1.5)$ & 0.01 \\
\hline \multicolumn{4}{|c|}{ 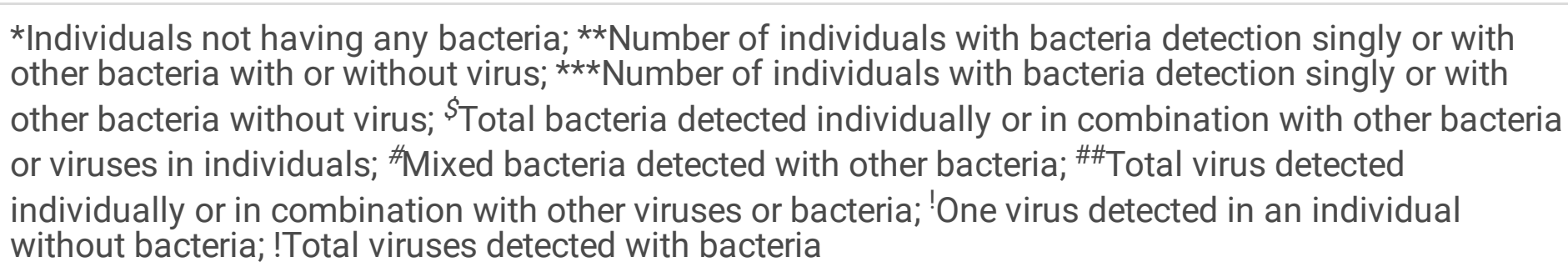 } \\
\hline
\end{tabular}

Table 4: Nasopharyngeal bacteria and viruses identified in children living with and without HIV 


\begin{tabular}{|c|c|c|c|}
\hline & Children living with HIV & HIV uninfected children & $\mathbf{P}$ \\
\hline & $\mathrm{n},(\%)$ & $\mathrm{n},(\%)$ & \\
\hline \multicolumn{4}{|l|}{ Bacteria } \\
\hline $\mathrm{n}$ & 43 & 40 & \\
\hline No. of individuals with bacteria only* & $18(42)$ & $16(40)$ & 0.86 \\
\hline No. of individuals with bacteria** & $30(70)$ & $26(65)$ & 0.64 \\
\hline Total S. pneumoniae $e^{\star \star *}$ & $16(37)$ & $15(37)$ & 0.98 \\
\hline Total S. aureus $s^{\star \star *}$ & $27(63)$ & $17(42)$ & 0.06 \\
\hline Total C. pneumoniae ${ }^{\star \star \star}$ & $1(2)$ & $1(2)$ & 0.96 \\
\hline$>1$ bacteria in one swab & $14(32)$ & $7(17)$ & 0.11 \\
\hline S. pneumoniae $+S$. aureus & $13(30)$ & $7(17)$ & 0.17 \\
\hline S. pneumoniae + C. pneumoniae & $1(2)$ & 0 & - \\
\hline \multicolumn{4}{|l|}{ Viruses } \\
\hline N & 49 & 43 & \\
\hline No. of individuals with virus! & $20(41)$ & $21(49)$ & 0.43 \\
\hline Human rhinovirus & $7(14)$ & $8(18)$ & 0.57 \\
\hline Human adenovirus & $7(14)$ & $2(4)$ & 0.12 \\
\hline Human bocavirus & $2(4)$ & $4(9)$ & 0.31 \\
\hline RSV & $1(2)$ & $1(2)$ & 0.92 \\
\hline Human coronavirus & $1(2)$ & $1(2)$ & 0.92 \\
\hline Human metapneumovirus & $1(2)$ & $1(2)$ & 0.92 \\
\hline Human parainfluenzavirus & $1(2)$ & - & - \\
\hline Influenza b virus & - & $4(9)$ & - \\
\hline Human enterovirus & - & - & - \\
\hline \multicolumn{4}{|l|}{ Viruses + Bacteria } \\
\hline $\mathrm{N}$ & 43 & 40 & \\
\hline Total viruses + bacteria & $12(28)$ & $10(25)$ & 0.76 \\
\hline
\end{tabular}


* Number of individuals with bacteria detection singly or with other bacteria without virus; ** Number of individuals with bacteria detection singly or with other bacteria with or without virus; ${ }^{\star \star \star} T o t a l$ number of bacteria detected individually or in combination with other bacteria in individuals; 'Number of individuals with viruses detected individually or in combination with other viruses or bacteria.

Table 5: Association between isolation of Streptococcus pneumoniae with respiratory viruses, and, between the density (Log copies/ml) of Streptococcus pneumoniae with viruses in the nasopharynx of children

\begin{tabular}{|llllllllll|}
\hline \multicolumn{9}{c}{ Pneumococcal colonization } & \multicolumn{5}{c|}{ Pneumococcal density } \\
& $\mathrm{n}^{\#}$ & OR* & $95 \% \mathrm{Cl}^{\star *}$ & $\mathrm{P}$ & $\mathrm{n}$ & Coeff & $95 \% \mathrm{Cl}$ & $\mathrm{P}$ \\
\hline Overall children & & & & & & & & \\
\hline Virus presence & 83 & 3.93 & $1.47-10.5$ & 0.006 & 31 & 3.603 & $.44-6.7$ & 0.027 \\
\hline 1 virus & 83 & 3.85 & $1.15-12.8$ & 0.028 & 31 & 0.533 & $-3.2-4.3$ & 0.77 \\
\hline$>1$ virus & 83 & 2.25 & $0.62-8.1$ & 0.21 & 31 & 5.06 & $1.1-9$ & 0.01 \\
\hline Rhinovirus & 83 & 3.13 & $0.99-9.9$ & 0.052 & 31 & 4.52 & $1.1-7.9$ & 0.01 \\
\hline Adenovirus & 83 & 6 & $1.12-32$ & 0.036 & 31 & 1.62 & $-2.7-6$ & 0.45 \\
\hline Children living with HIV & & & & & & & & \\
\hline Rhinovirus & 43 & 15.6 & $1.66-146$ & 0.016 & 16 & 4.22 & $-0.2-8.6$ & 0.06 \\
\hline Rhinovirus + S. aureus & 43 & 8.7 & $1.42-54$ & 0.019 & & & & \\
\hline Adenovirus & 43 & 4.16 & $0.66-26$ & 0.12 & 16 & -0.46 & $-6.1,5.1$ & 0.86 \\
\hline HIV uninfected children & & & & & & & & \\
\hline Rhinovirus & 40 & 1 & $.20-4.9$ & 1 & 15 & 2.7 & $-1.9-7.3$ & 0.23 \\
\hline Adenovirus & 40 & NA*** & NA & NA & 15 & 2.77 & $-2.7,8.3$ & 0.3 \\
\hline
\end{tabular}

${ }^{*} \mathrm{n}$, number of observations; ${ }^{\star} \mathrm{OR}$, odds ratio; ${ }^{* \star} \mathrm{Cl}$, confidence interval; ${ }^{\$}$ Regression coefficient; ${ }^{\star \star \star} \mathrm{NA}$, not available. 